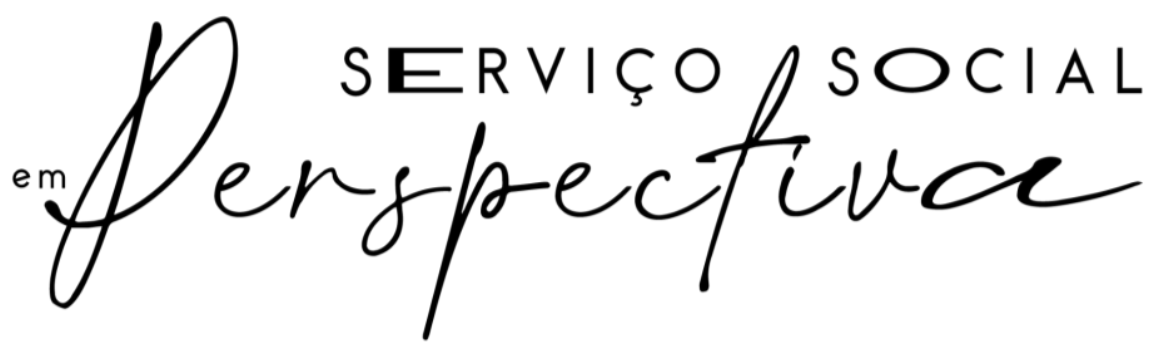

Montes Claros (MG), volume 6, número 1. jan./jun. 2022. I ISSN 2527-1849

\title{
POBREZA E SEU ENFRENTAMENTO SOB A HEGEMONIA NEOLIBERAL NO BRASIL
}

POVERTY AND ITS FIGHTING UNDER NEOLIBERAL HEGEMONY IN BRAZIL

Fabricio Fontes de Andrade llzamar Silva Pereira ${ }^{2}$

\begin{abstract}
Resumo: Este artigo aqui apresentado se realizou através de revisão bibliográfica sobre Pobreza e seu enfrentamento na realidade social brasileira sob a hegemonia neoliberal na conjuntura atual. Deste modo, objetivou-se alcançar uma maior compreensão sobre os preceitos teóricos que embasam o combate à pobreza no pensamento social neoliberal, seus elementos fundantes e suas principais propostas de direcionamento do enfrentamento a pobreza no contexto brasileiro. Os autores neoliberais analisados, via de regra, vinculam a superação da pobreza em questões de ordem individual desvinculando a dinâmica da pobreza de dimensões estruturais da pobreza na sociedade brasileira, ou identifica na esfera estatal a gênese e desenvolvimento da pobreza. Notase que o governo brasileiro, cuja perspectiva conservadora se vincula ao neoliberalismo mais arraigado, busca atingir crescimento econômico com a estruturação de uma proteção social restritiva e focalizada vinculada a mercantilização da proteção social lucrativa, do mesmo modo que a distribuição de transferências de renda desvinculadas da oferta serviços sociais universais ao conjunto da população brasileira.
\end{abstract}

Palavras-chave: Neoliberalismo: Politica Social; Pobreza; Brasil.

Abstract: This article presented here was carried out through a bibliographical review on Poverty and its confrontation in the Brazilian social reality under the neoliberal hegemony in the current situation. Thus, the objective was to achieve a greater understanding of the theoretical precepts that support the fight against poverty in neoliberal social thinking. its founding elements and its main proposals for directing the fight against poverty in the Brazilian context. The neoliberal authors analyzed, as a rule, link the overcoming of poverty to issues of an individual order.

\footnotetext{
1 Assistente Social. Graduação em Serviço Social pela Unimontes. Mestrado em Desenvolvimento Social pela Unimontes, Doutorado em Serviço Social pela Universidade Federal do Rio de Janeiro. Professor Adjunto nível III da Universidade Federal do Recôncavo da Bahia. Membro do Grupo de Pesquisa em Pobreza, Assistência Social e Território - GEPAST. ORCID: 0000-0001-5624-8222 Link do Currículo Lattes: http://lattes.cnpq.br/4108035523879429 E-mail: fabricio@ufrb.edu.br

2 Assistente Social. Graduação em Serviço Social pela Universidade Federal do Rio Grande do Norte. Mestrado em Serviço Social pela Universidade Federal do Rio Grande do Norte, Doutorado em Serviço Social pela Universidade Federal do Rio de Janeiro. Professora Adjunta nível III da Universidade Federal do Recôncavo da Bahia. Membro do Grupo de Pesquisa em Pobreza. Assistência Social e Território - GEPAST. Link do Currículo Lattes: http://lattes.cnpq.br/7904127288821038 E-mail: ilzamarpereira@ufrb.edubr
} 
detaching the dynamics of poverty from structural dimensions of poverty in Brazilian society, or identify the genesis and development of poverty in the state sphere. Note that the Brazilian government, whose conservative perspective is linked to the most entrenched neoliberalism, seeks to achieve economic growth by structuring a restrictive and focused social protection linked to the commodification of profitable social protection, in the same way as the distribution of cash transfers unrelated to the provision of universal social services to the entire Brazilian population. Key-words: Neoliberalism; Social Policy: Poverty: Brazil.

INTRODUÇÃO

A análise das perspectivas sobre a pobreza e seu enfrentamento pressupõe colocar esta categoria situada em sua totalidade histórica, levando-se em conta as dinâmicas assumidas pelo capital em seus diversos modos de acumulação configurados durante suas fases. Do ponto de vista historiográfico a humanidade convive com formas de pobreza e seus desdobramentos, certamente, antes do desenvolvimento da sociedade capitalista. Neste contexto pré-capitalista a pobreza decorre da incapacidade de geração de riquezas ou pela escassez de gêneros alimentícios. Situação que se desdobra - e precisamente acarretou em alguma medida - na pobreza de milhões de pessoas, levavam à morte um número também significativo de pessoas por completa incapacidade social de geração de riquezas.

Se a pobreza é anterior ao capitalismo, sob a organização produtiva do capital esta assume formas marcadamente distintas das formas anteriores. Sob o ordenamento do capital a pobreza se afirma e persiste mesmo diante do crescimento significativo da abundância e do desenvolvimento inédito da capacidade produtiva. Visualiza-se, portanto, a pobreza como uma contra face do desenvolvimento ampliado do sistema capitalista, não como resultante de uma incapacidade produtiva.

No desvelamento do século XXI, a partir do desenvolvimento da acumulação capitalista, em que se impôs via processos de liberalização, desintermediação, e desregulamentação de mercados com predominância da esfera financeira, pressionam-se cada vez mais os Estados nacionais a abandonar as formas de intervenção baseadas nos sistemas de proteção social típicos dos Estados de Bem-Estar Social, e adotar formas mais flexiveis e restritivas de proteção social. Este processo é estudado por Chesnais (2005) e denominado de Regime de Acumulação com dominância financeira ${ }^{3}$.

\footnotetext{
3 Para nosso estudo, convém destacar que a dinâmica da dominância financeira tem como consequência a dependência dos paises, sobretudo os em desenvolvimento, de créditos e investimentos estrangeiros, traz consequências nefastas para a configuração das politicas sociais pois, acarreta o manejo macroeconômico que objetiva a atração de capital fictício para financiar os déficits nos orçamentos. Como a fonte de recursos de politicas sociais é a mesma que remunera o esperado pelo capital fictício, os investimentos sociais se encontram em prejuizo vis a vis a remuneração de investidores rentistas.
} 
Partindo da proeminência da parte financeira do capital, que passa a comandar e hegemonizar desde então os processos de acumulação, configuram-se novas perspectivas de organização da sociedade civil e do Estado, em que. "(..) os investimentos financeiros tornam a relação social do capital com o trabalho aparentemente invisivel". (IAMAMOTO, 2007. p. 21). Nesse contexto, são atacados de maneira central a legitimidade e as reivindicações das instituições dos trabalhadores que questionavam o ideário neoliberal. Nota-se um processo de invisibilidade da "questão social" que passa a ser gerida tecnicamente em suas franjas, ou de maneira fragmentada em suas manifestações isoladamente.

Neste processo, emerge desde então, sob a tutela do FMl e seus intelectuais vinculados ao ideário neoliberal, a centralidade do combate à pobreza como enfoque privilegiado de intervenção a que se destinam as politicas sociais. Desde então, as políticas sociais vêm sendo marcadamente direcionadas aos pobres, em especial em contextos periféricos como o contexto brasileiro, no qual,

Adquirem destaque políticas sociais voltadas à preservação dos mínimos vitais dos segmentos da crescente população excedente lançados ao pauperismo: e ao seu controle político, preservando o direito à sobrevivência de imensos contingentes sociais e alimentando o consenso de classe necessário à luta hegemônica (IAMAMOTO, 2009. p. 342; 343).

Diante da proeminência e do destaque que ganham medidas compensatórias da pobreza no contexto da pandemia do COVID-19, é mister como objetivo deste artigo, analisar criticamente pressupostos implícitos na estratégia de enfrentamento da pobreza neste cenário. Diante da discussão até aqui empreendida, ganha centralidade um elemento norteador deste artigo: Quais os principais pressupostos teóricos neoliberais no enfrentamento da pobreza que emergem no periodo pandêmico?

No desenvolvimento do artigo, com vistas a desvelar as determinações da questão norteadora da investigação, trabalha-se de maneira articulada com três categorias: Estado, Pobreza e Politica Social. A escolha destas categorias não é aleatória, uma vez que estas se articulam em um todo complexo, que possibilita não só estabelecer os nexos explicativos sobre a pobreza, bem como, possibilita articular o entendimento do desenho de enfrentamento da pobreza operacionalizado nas políticas sociais contemporâneas, fruto de ações e/ou omissões do Estado sob hegemonia neoliberal em sua dimensão ampliada.

No que concerne à exposição do artigo, esta se dividirá em três momentos em seu desenvolvimento, um primeiro debate conceitual das categorias Estado, Política Social e Pobreza, em um segundo momento uma análise dos fundamentos conceituais neoliberais do combate à pobreza e em terceiro momento uma análise crítica das propostas gerais de reforma da proteção social brasileira que se vincula à inspiração neoliberal. 


\section{ESTADO, POLÍTICA SOCIAL E POBREZA}

A categoria teórica do Estado é compreendida neste artigo como sendo uma relação social, que incorpora parcialmente demandas da classe trabalhadora, mas que tende primordialmente a reproduzir os interesses da classe dominante. Assim, não se trata da busca da estrutura ontológica do Estado e de seu poder, mas de seu conteúdo real e contraditório. que embora hegemonicamente determinado, é permeável a incorporação de demandas contra hegemônicas, limitadas pelo poder de mobilização e pela conservação da forma capitalista de produção.

O Estado deixa de ser pensado como um ente fora das contradições societárias, como nas tradições liberais/contratualistas - fruto de um contrato social, ou mesmo de uma forma divinizada, universalizadora dos diversos interesses de maneira ética, que, portanto, se encontraria separado das contradições sociais. Em seu caráter contraditório, reflexo das dinâmicas de uma sociedade dividida em classes e projetos societários antagônicos, o Estado não pode se posicionar de maneira a incorporar somente demandas das classes que o dominam. Diante deste conteúdo permeável, é possivel destacar na configuração do Estado importantes conquistas oriundas de reivindicações e lutas, operárias, populares e de segmentos da classe trabalhadora que são inscritos via direitos sociais na dinâmica institucional. Dessa forma, o controle do Estado torna-se dimensão indispensável das estratégias das classes sociais antagônicas que querem impor seus valores ao conjunto da sociedade como socialmente válidos.

Assim, de acordo com Coutinho (1996) Estado integra duas instâncias de exercício da dominação, sociedade política (coerção) e sociedade Civil (consenso). Nessas instâncias, integradas no Estado Ampliado, este impõe o conteúdo ético das classes dominantes no âmbito da sociedade civil.

Compondo o "Estado Integral" ou "Estado Ampliado4", a sociedade civil seria a instância que operaria a função de garantir a hegemonia de um determinado grupo ou classe social através dos chamados "aparelhos privados de hegemonia". A sociedade civil, com seus aparelhos privados de hegemonia seria.

\footnotetext{
${ }^{4}$ Dentre os ganhos da interpretação ampliada dada ao Estado pelo pensamento gramsciano está o fato de que [...] a teoria ampliada do Estado é a base que permite a Gramsci responder de modo original à questão do fracasso da revolução nos paises ocidentais: esse fracasso ocorreu, supõe Gramsci, porque não se levou na devida conta a diferença estrutural que existe entre, por um lado, as formações sociais do 'Oriente' lentre as quais se inclui a Rússia czarista), caracterizada pela debilidade da sociedade civil em contraste com o predomínio quase absoluto do Estado-coerção; e por outro, as formações sociais do 'Ocidente', onde se dá uma relação mais equilibrada entre sociedade civil e sociedade politica, ou seja, onde se realizou concretamente a 'ampliação' Estado (COUTINHO, 1992, p.89).
} 
(...) $\bigcirc$ conjunto de instituições responsáveis pela representação dos interesses dos diferentes grupos sociais, bem como pela elaboração e/ou difusão de valores simbólicos, de ideologias, compreendendo o sistema escolar, os partidos políticos, as igrejas, as organizações profissionais, os sindicatos, os meios de comunicação, as instituições de caráter científico e artístico. (COUTINHO, 1996, p.54)

Neste campo, as classes dominantes buscam através do consenso social garantir aliados a seus projetos societários, seus valores e ideologias. Portanto, torna-se fundamental a formulação e ampliação dos aparelhos privados para a consolidação da hegemonia na sociedade civil.

Por sua vez, a sociedade política enquanto instância do Estado Ampliado se compõe por aparelhos responsáveis diretamente ligados à dominação por coerção, operada pelos chamados aparelhos coercitivos do Estado. A sociedade política, composta por seus aparelhos coercitivos seria composta pelo:

(...) conjunto de aparelhos por meio dos quais a classe dominante detém ou exerce o monopólio legal ou de fato da violência; trata-se, portanto, dos aparelhos coercitivos do Estado, encarnados nos grupos burocrático-executivos ligados às forças armadas e policiais e à aplicação das leis (COUTINHO, 1996, p.53)

Neste sentido, entendemos que a concepção de Estado sob inspiração gramsciana perpassará a discussão de política social implícita nas análises das estratégias de combate à pobreza empreendidas neste artigo.

Assim, entendendo ser o Estado, portanto, responsável enquanto "capitalista ideal total", de entrelaçar as funções integradoras e repressivas para garantir as condições gerais de produção, Mandel (1982) sustenta que:

As funções superestruturais que pertencem ao domínio do Estado podem ser genericamente resumidas como a proteção e a reprodução da estrutura social las relações de produção fundamentais), à medida que não se consegue isso com os processos automáticos da economia" (MANDEL, 1982, p. 333).

Entende-se deste modo, que as ações do Estado na intervenção junto às manifestações da "questão social", buscam garantir e manter articuladamente condições de reprodução do modo de produção capitalista, e a organização das suas relações sociais. Porém, mesmo que garanta as condições de reprodução do capital, as ações estatais não suprimem as contradições destas relações sociais, basicamente, por que as mesmas são estruturais. 
Assim, enquanto instância que perpetua valores de uma classe que o domina, - embora não de maneira total - entende-se que o Estado surge de maneira concomitante, e se metamorfoseia na mesma medida da configuração do sistema capitalista enquanto reprodutor da vida social.

Em relação a esta dinâmica do Estado capitalista enquanto mecanismo de reprodução do sistema do capital. Meszaros (2011) assevera que o Estado complementa as estruturas do sistema do capital se caracterizando como estrutura totalizadora de comando político do capital. (p.106)

Para Meszaros (2011), a funcionalidade do Estado demonstra ainda que para a manutenção necessária do sistema sócio metabólico do capital, a ação corretiva do Estado é fundamental no sentido de manter intocados os traços estruturais do sistema capitalista, pois, para o autor.

É literalmente vital para manter sob controle lainda que incapaz de eliminar completamente) os antagonismos que estão sempre surgindo da dualidade disruptiva dos processos socioeconômicos e politicos de tomada de decisão sem os quais o sistema do capital não poderia funcionar adequadamente. (p.122)

Um dos mecanismos lançados como forma corretiva presentes na ação do Estado está a política social. A politica social como forma de intervenção nas situações de pobreza enquanto manifestação da "questão social" é interpretada em suas contradições, pois as mesmas "são objeto de luta entre diferentes forças sociais, em cada conjuntura, não constituindo, pois, o resultado mecânico da acumulação nem a manifestação exclusiva do poder das classes dominantes ou do Estado (FALEIROS, p.33, 2009)

Apesar de não ser mecanicamente identificada como funcional, única e exclusivamente a uma ou outra classe ou fração de classe, em um sentido geral reflete as condições mais amplas das correlações de força presentes na sociedade, melhor servindo a quem melhor a controlar.

Assim, as politicas sociais refletem, mas não de maneira direta, o resultado de conflitos e relações que se operam no âmbito de diferentes interesses de classes e frações de classes distintas, uma vez que os sujeitos coletivos disputam o seu controle e direcionamento a fim de obter ganhos satisfatórios para os segmentos que representam.

Por ser condicionada por processos de disputas e formação de consensos sociais com vistas à consolidação de hegemonia, a política social reflete em seu conteúdo direcionamentos mais gerais do Regime de acumulação prevalecente em um momento histórico. Assim as politicas sociais acabam sendo analisadas em uma perspectiva de totalidade. "como uma mediação entre economia e política, como resultado de contradições estruturais engendradas pela luta de classes e delimitadas pelos processos de valorização do capital" (BEHRING, 2009b. 302). Desta feita, seu conteúdo varia de acordo com o contexto econômico, cultural e político de cada sociedade, embora preservando elementos gerais do Regime de Acumulação. 
A centralidade da categoria pobreza e seu enfrentamento se afirmam pela intrínseca relação que a pobreza, enquanto manifestação da "questão social", tem com as formas de produção capitalista e o modo pelo qual se articulam formas de enfrentamento de acordo com as características de um Regime de Acumulação específico, sem descartar o contexto sociopolítico de sua intervenção. Logo, entende-se que a pobreza que longe de ser um desdobramento natural da vida em sociedade, é fruto e condição necessária do Modo de Produção Capitalista, tal como exposto por Marx (2014) na lei geral de acumulação capitalista. Neste sentido, pensar a pobreza no capitalismo, significa necessariamente pensar o seu resultante, que é o modo de produção de riquezas sob o capitalismo e sua consequente apropriação privada frente a uma produção cada vez mais socializada.

A partir desta dinâmica, visualiza-se que situações de pobreza se agudizam na sociedade capitalista como uma refração central das modificações do modo de produção capitalista. A crise 5 do capital desencadeada na década de 1970 acarretará na inflexão do padrão de acumulação Fordista-keynesiano, cujas consequências se desdobram na configuração de um novo padrão de acumulação, denominado acumulação flexivel, que definirá novas funções ao Estado e a hegemonia financeira neste regime de acumulação.

Nos marcos do capitalismo, definir de maneira conceitual e instrumental o que se determina enquanto pobreza não é de modo algum uma tarefa consensual. Existem várias perspectivas de determinação sobre qual seria o limiar para se delimitar a pobreza, os grupos sociais que seriam pobres e não pobres. Definir a pobreza passa necessariamente pelo debate em torno de sua mensuração, cuja definição não é isenta de polêmicas e debates sobre a funcionalidade da linha de pobreza utilizada para mensurar a dimensão da pobreza em uma sociedade capitalista.

Diante dos elementos apresentados em relação à mensuração da pobreza na sociedade capitalista, visualiza-se uma interpretação da pobreza individualizada enquanto manifestação da questão social por parte dos liberais. Para estes, as capacidades individuais determinam a medida da pobreza, seja em suas causas de incapacidade de geração de renda, seja como um problema natural decorrente de limites individuais, uma vez que as atribuições de seu enfrentamento estariam centradas em disposições individuais em conseguir o sucesso ou não no mercado de trabalho, restando aos incapacitados, física ou moralmente, esquemas de alivio da pobreza. A opção liberal por naturalizar as causas da pobreza impede que se chegue ao cerne do processo que acarreta a geração da pobreza, fundado na forma de produzir capitalista.

\footnotetext{
${ }^{5}$ Não cabe neste momento aprofundar a discussão sobre o conteúdo das crises no capitalismo, nem mesmo esse é o objeto central desta tese. No entanto uma aproximação a este fato é fundamental para o entendimento das funcionalidades das políticas de combate à pobreza sob o capitalismo, neste sentido, irei discutir o caráter endógeno da crise capitalista no decorrer dos capitulos desta tese, destacando a especificidade da crise em cada passagem dos Regimes de Acumulação.
} 
Por sua vez, nos contextos periféricos, as transformações nas definições das atribuições do Estado sob a influência dos preceitos neoliberais seguiram ritmos diferenciados de acordo com cada país. Porém, destaca-se que via de regra os ajustes neoliberais se empreenderam sob o comando e direção do Fundo Monetário Internacional - FMl e Banco Interamericano do Desenvolvimento - BID entre outros organismos internacionais. De acordo com Anderson (1995), em virtude dos frágeis sistemas de proteção social na região, fruto de desenvolvimento desigual e combinado, as consequências do ajuste neoliberal serão muito mais sentidas nos paises da periferia do capitalismo.

\section{A POBREZA NO NEOLIBERALISMO PROPOSTO POR HAYEK}

Se o liberalismo passou pela metamorfose de ser uma teoria revolucionária na transição do feudalismo ao capitalismo, com forte ataque aos privilégios e à servidão feudal, e converteu-se posteriormente em um sustentáculo reacionário da ordem do capital, o neoliberalismo tem por característica seu contorno essencialmente conservador. Ou seja, se - liberalismo fazia forte oposição ao conteúdo das relações sociais e ao Estado feudal, o neoliberalismo elege como adversário prioritário as estruturas do Estado intervencionista sob o regime fordista keynesiano de Acumulação.

Apesar de se autoproclamar adversário das propostas keynesianas de regulação social e reiterar a necessidade de se retomar os pressupostos de livre mercado contidos no liberalismo clássico interditados pelo pensamento de Keynes e sua heterodoxia, é necessário realizar algumas precisões quanto a este fato de um possivel protagonismo de Hayek enquanto defensor do liberalismo clássico em detrimento de um Keynes não liberal. É importante destacar que diante dos limites e objetivos deste trabalho, optamos por analisar a concepção de pobreza no precursor do neoliberalismo, embora não se desconheça a contribuição para a análise neoliberal de autores como Firedman entre outros.

Neste sentido, se temos conforme Montaño (2010) a sintese do pensamento neoliberal em Hayek, a identificação operada pelo autor neoliberal entre keyensianismo e socialismo, Welfare State e Totalitarismo, são na verdade duas mistificações de uma disputa dentro de matizes diferenciados do pensamento liberal. Desta forma, é importante asseverar que a oposição essencial proposta por Hayek entre Liberalismo e keynesianismo somente faria sentido se a estratégia keynesiana rompesse com os pressupostos da acumulação ampliada do capital. Entende-se, portanto, a partir da análise da linha argumentativa neoliberal vis a vis o pensamento keynesiano, que não se visualiza necessariamente a existência de forte antagonismo entre elas para além da dimensão argumentativa, pois necessariamente não se trata de

(...) um confronto entre (neo) liberais e não liberais, entre defensores dos interesses capitalistas e contrários a eles, mas uma oposição estratégica entre liberais (de distintas tendências, de diferentes contextos históricos, e talvez de distintas frações: 
industrial e financeiral que visam ao mesmo desenvolvimento da acumulação capitalista. " (MONTAÑO, 2010, p.86)

Assim, feitas estas observações quanto ao pensamento de Hayek, nota-se que em seu diagnóstico da situação do desenvolvimento capitalista, os neoliberais sustentam que a opção keynesiana de regulação econômica destina a sociedade à servidão de depender cada vez mais de intervenções estatais, sendo que em sua análise os neoliberais afirmam que "o fascínio de expressões vagas mas populares como "pleno emprego" pode conduzir à adoção de medidas extremamente insensatas, em que a frase categórica e irresponsável do idealista radical, "isso deve ser feito a todo custo", pode produzir os maiores danos. (HAYEK, 2010, p.194)

Neste contexto analisado, os neoliberais por sua vez, mantém a perspectiva analitica do liberalismo clássico, superando e reatualizando suas temáticas de individualização e moralização da "questão social", porém, agora voltadas para o combate e questionamento das estruturas do Estado de Bem-estar Social, que na análise dos neoliberais levariam a acomodação dos pobres, retirando-lhes o impeto ao trabalho.

A tentativa neoliberal de decifrar os problemas sociais centra sua análise no caráter virtuoso da liberdade a ser efetivada no âmbito do mercado, em que este seria a instância privilegiada da solução de situações de pobreza. Desta forma. Hayek (2010) sustenta a necessidade de organização de um estado restrito na intervenção social. Este Estado seria limitado a um conjunto de normas gerais, não influindo sobre medidas particulares dos individuos e sua possibilidade de comprar e vender no âmbito do mercado. Assim. o Estado sob esta perspectiva não deveria se responsabilizar por oferta de serviços sociais universais, pois na perspectiva neoliberal o Estado a ser buscado deve se restringir à administração orçamentária e das instituições da justiça.

No entanto, ao apontar tais medidas de restrição da ação estatal, a proposição neoliberal não resgata a ideia do lasses fare do liberalismo clássico simplesmente, uma vez que os neoliberais não prescindem de um Estado que regule e incentive a concorrência e a competição capitalista, sendo preferível um Estado que garantisse o:

A doutrina liberal é a favor do emprego mais efetivo das forças da concorrência como um meio de coordenar os esforços humanos, e não de deixar as coisas como estão. Baseia-se na conviç̧ão de que, onde exista a concorrência efetiva, ela sempre se revelará a melhor maneira de orientar os esforços individuais. Essa doutrina não nega, mas até enfatiza que, para a concorrência funcionar de forma benéfica, será necessária a criação de uma estrutura legal cuidadosamente elaborada, e que nem as normas legais existentes, nem as do passado, estão isentas de graves falhas. (HAYEK, 2010, p.58) 
De acordo com a citação, visualizamos que os neoliberais não se posicionam para a inexistência de um Estado, mas que este seja limitado a determinados enfoques e aspectos da vida social que sejam imprescindiveis para a manutenção da liberdade de ação e concorrência como mecanismo de regulação das relações sociais.

Diante deste quadro, os neoliberais, cujo pensamento restava obscurecido pelo sucesso das medidas de regulação keynesiano-fordistas dos 30 anos gloriosos do capitalismo, ganham espaço sociopolítico em virtude da manifestação da crise da taxa de lucro, e apontam que as indesejadas intervenções estatais são a causa da crise, elegendo o Estado de Bem-Estar social como o causador da crise que então se manifestara. Para Harvey (2008, p.03) as ideias neoliberais sintetizam-se no fato de que:

O neoliberalismo é em primeiro lugar uma teoria das práticas político-econômicas que propõe que o bem-estar humano pode ser melhor promovido liberando-se as liberdades e capacidades empreendedoras individuais no âmbito de uma estrutura institucional caracterizada por sólidos direitos a propriedade privada, livres mercados e livre comércio.

Assim, para os neoliberais era necessário empreender soluções no sentido de liberalizar as estruturas econômicas amarradas pelas regulações keynesianas e incentivar o protagonismo individual e a garantia de condições para a manutenção da propriedade privada.

Os neoliberais trabalham com a necessidade de se ter um nivel natural e autorregulado de desemprego, reformas fiscais e liberalização financeira. Neste sentido, a liberalização dos mercados é acompanhada de uma forte restrição de ganhos salariais, e ao mesmo tempo em que se rompem os pactos de regulação keynesiana, abre-se espaço para grupos de pressão provenientes do capital financeiro determinar o conteúdo da política econômica.

Como mecanismo concomitante às mudanças no processo produtivo, as prerrogativas de ação do Estado foram também questionadas e apontadas como geradoras da crise e das dificuldades pelas quais passava a economia. Diante destas criticas, ganham terreno as medidas neoliberais, que justificavam a crise como resultante da ampliação dos gastos sociais do excesso de poder dos sindicatos.

Em sua alternativa para superar os efeitos da crise capitalista, as politicas neoliberais se orientaram pela limitação financeira distanciando-se de pressupostos keynesianos, tais como o pleno emprego. Do mesmo modo, avançaram medidas para aumentar a participação privada na oferta de serviços, com a privatização de empresas estatais. Em outro aspecto, medidas de reforma da ação estatal e enfraquecimento do compromisso capital/trabalho marcante do periodo keynesiano foram implementadas como justificativa para se sedimentar o retorno do crescimento econômico. 
Em sua perspectiva de pensar uma "boa sociedade". Hayek (2010) sustenta que a ação do Estado deveria se restringir a garantir a liberdade dos individuos para que estes pudessem discernir sobre as escolhas feitas no âmbito do mercado de trabalho, restando a intervenção estatal a ação emergencial nas situações de calamidade e extrema pobreza. Para este autor, "[...] quanto mais o Estado planeja, mais difícil se torna para o indivíduo traçar seus próprios planos". (HAYEK, 2010, p.92)

Na perspectiva ideopolítica neoliberal hegemônica a partir de crise capitalista de 1973. configurando o padrão de acumulação flexível (HARVEY 1993), o enfrentamento da pobreza se efetiva e se caracteriza ainda na esfera da distribuição, porém, como problema de escassez. e também aprofunda o seu fundamento sustentado em seu caráter individual. Neste sentido, advoga-se o retorno ao Estado de práticas pretéritas de enfrentamento da pobreza como a filantropia, a solidariedade e as sociabilidades primárias como a familia e a comunidade, e em especial o discurso renovado das ONGs.

Em relação a pobreza e seu enfrentamento, as propostas neoliberais explicitadas por Hayek (2010) fundamentam uma concepção de Estado mínimo e de pobreza como consequências "naturais" de insucesso e incapacidades pessoais. De acordo com Hayek (2010) a ação do estado deve ser conduzida de maneira neutra, longe das pressões e influências da esfera politica, garantindo maior funcionalidade do aparelho do Estado às necessidades econômicas, tal qual a esfera privada, no sentido que, "para se realizar um planejamento eficaz, a gestão econômica deve ser afastada da área politica e confiada a especialistas funcionários permanentes ou organismos autônomos e independentes". (HAYEK 2010, p. 80)

Portanto, para o pensamento neoliberal contido em Hayek (2010), o Estado deve ser neutro em relação as disputas sociais operando como uma estrutura apartada da realidade. mas sempre direcionado ao dever originário de se garantir a liberdade e a propriedade privada. Assim, para Hayek qualquer ação estatal na regulação econômica romperia com as prerrogativas do Estado democrático de direito ao garantir direitos sociais para a população. que romperiam o status e o merecimento, configurando, portanto, em sua visão, uma estrutura de privilégios em relação às disputas a serem operadas na sociedade.

Por sua vez, quanto a estes "privilégios", sugere o autor que, questionada sobre a justeza das medidas sociais típicas do Estado de bem-estar social, nenhuma outra pessoa deveria conscientemente aceitar, e se estes direitos forem impostos a alguém, deveriam ser interpretados como privilégios, que acarretariam a supressão da vontade individual por um lado, e em outra dimensão a limitação da ação das livres forças do mercado. Em relação a este aparato de proteção social, a perspectiva neoliberal entende que este levaria a estagnação das iniciativas individuais, uma vez que, nas palavras do autor fundador do neoliberalismo:

(...) torna-se improvável que um individuo dê o melhor de si por muito tempo, a menos que seu interesse esteja diretamente envolvido. A maioria das pessoas necessita, em geral, de alguma pressão externa para se esforçar ao máximo. Assim, o problema dos 
incentivos é bastante real, tanto na esfera do trabalho comum como na das atividades gerenciais. (HAYEK, 2010, p.131)

Nota-se que a retórica neoliberal supõe a impossibilidade de garantia de regras e proteções que norteiam as políticas sociais no quadro do Estado de bem-estar social, devido ao processo crise fiscal e excessiva regulação estatal. Tais ações acarretariam estímulos contraproducentes no comportamento dos individuos, tal como a dependência parasitária dos individuos à custa do esforço das coletividades, sendo, a via mais acertada para a superação da crise e retorno do crescimento, a desarticulação entre emprego e sistemas universais de proteção social.

Em seu encadeamento de argumentos, a perspectiva neoliberal de Estado se funda na ideia de que o bem-estar coletivo, realizado através da ação individual, é um resultado inconsciente da motivação individual e racional pelo ganho econômico. Não obstante, o papel do Estado deveria ser periférico em relação à dinâmica social (a mão invisível), e o mercado deveria ser livre e não sofrer interferências.

A única ação do Estado que poderia ser exequível na visão de Hayek (2010) seria aquela que garantisse condições mínimas de sobrevivência biológica, sem romper com as livres forças do mercado. Neste ponto, a redução das responsabilidades estatais propostas por Hayek, não supõe que modo algum a superação ou eliminação da pobreza.

Logo, torna-se, estratégico para o pensamento neoliberal a oferta de serviços precarizados, focalizados e seletivos por testes de pobreza, que não ocupassem espaços passiveis de serem ocupados pelo mercado ou entidades assistenciais privadas. Neste sentido, todo conteúdo de direitos deveria ser remercantilizados, restando à ação estatal medidas emergenciais, que não coloquem em risco a liberdade de concorrência, e que mantenha a capacidade vital de trabalho

Do mesmo modo, como podemos analisar a partir de suas argumentações, o autor encara a pobreza como resultado de uma incapacidade individual que se fundamenta na impossibilidade de competição no mercado de trabalho, pois para o autor, a única esfera aceitável de intervenção do Estado no que concerne as situações de pobreza seria o atendimento ao conjunto de condições mínimas de sobrevivência àqueles indivíduos comprovadamente pobres e/ou que tenham incapacidade para ocupar-se no mercado de trabalho gerido pela concorrência entre os trabalhadores.

Visualiza-se, portanto, uma reatualização do pensamento liberal clássico em relação a aptidão ou não em relação a participação no mercado de trabalho, apontando a aceitabilidade de intervenções destinadas aos comprovadamente mais pobres e incapazes de produzir economicamente. Nessa perspectiva, a proposta original a ser adotada pelos ditames neoliberais se ancora na redução dos gastos sociais no trinômio: Focalização, privatização e descentralização, sendo as políticas sociais reconfiguradas no sentido se restringirem aos 
segmentos de menor renda em detrimento serviços universais característicos da forma de regulação keynesiano-fordista.

Continuando com as delimitações da ação de enfrentamento da pobreza, Hayek (1977) afirma que a ação do estado não pode incidir sobre a liberdade econômica, sobre a venda da força de trabalho, sendo a ação estatal marginal e residual em relação as forças naturalmente ajustadas dos mercados. Ou seja, a atuação do Estado não deve restringir ou desincentivar o mercado, propondo, portanto, uma ação estatal que se organiza e justificase no fato de que

\footnotetext{
Não há dúvida de que a segurança adequada contra as privações, bem como a redução das causas evitáveis do fracasso e do descontentamento que ele acarreta, deverão constituir objetivos importantes da politica de governo. Mas, para que essas tentativas sejam bem-sucedidas e não destruam a liberdade individual, a segurança deve ser proporcionada paralelamente ao mercado, deixando que a concorrência funcione sem obstáculos. Certa medida de segurança é indispensável à preservação da liberdade. porque a maioria dos homens só aceita de bom grado o risco inevitavelmente implícito na liberdade se este não for excessivo. (HAYEK, 2010, p.137)
}

Tal proposta de ação estatal e as consequências das medidas neoliberais acarretou uma importante contradição em seus resultados alcançados. Se por um lado os gastos não foram reduzidos, por outra perspectiva nota-se uma diminuição de seu ritmo de crescimento e alteração de suas fontes de financiamento, com proeminência de impostos cada vez mais regressivos e incidentes sobre o conjunto da classe trabalhadora, sobretudo a de menor rendimento, e maior isenção aos grandes rentistas e especuladores, liberando o capital para a realização de taxa de lucro.

\section{ANÁLISE CRÍTICA DA PROPOSTA DE ENFRENTAMENTO DA POBREZA PELOS NEOLIBERAIS NO CONTEXTO BRASILEIRO}

É importante destacar que as medidas neoliberais levaram, no contexto regional, além de pífios resultados econômicos, a uma desestruturação social vigorosa, que levou a revisão de seus cânones mais inflexíveis e a adoção de medidas mais sofisticadas de intervenção frente ao quadro de clara regressividade social decorrentes das primeiras experiências de implementação de medidas de ordem neoliberal.

Por outro lado, as medidas de ajuste estrutural resultam em repercussões para a dinâmica das políticas sociais brasileiras em momento que deveriam estar em início de consolidação devido a aprovação da Constituição Federal de 1988. A estratégia neoliberal para as políticas sociais no Brasil se pautou em três pressupostos principais, focalização, privatização e descentralização. 
Esta tríade de iniciativas engendrada na introdução do neoliberalismo buscava consolidar uma nova forma de intervenção pública, que marginalizasse a responsabilidade estatal e o caráter de universalidade desenhado na Constituição Federal de 1988 em relação às politicas públicas, e impor uma agenda de políticas sociais focalizadas na pobreza absoluta sob o argumento de se superar os traços eminentemente desiguais do sistema de proteção social brasileiro.

O diagnóstico dos pressupostos neoliberais parte da afirmativa de que o Estado seria gerador de distorções e privilégios, e que este deveria ser reformado para adequar-se à nova realidade. Como desdobramento do diagnóstico neoliberal sobre o Estado no Brasil, os caminhos trilhados para a superação da chamada crise do Estado burocratizado operavam a apologia de virtudes inerentes do mercado na regulação social, e o papel residual do Estado, em que "Esta redução é vista como condição para garantir os 'direitos civis' (ou, mais precisamente, a liberdade de mercado e a propriedade privada.) " (Coutinho, 2000, p. 116).

Assim sendo, como alternativa para solução dos crescentes problemas sociais emergem as medidas focalizadas de enfrentamento a pobreza, apontando a necessidade de se priorizar os mais pobres na alocação das políticas sociais, rompendo em tese, o caráter injusto das politicas sociais de perspectiva universal. No entanto, no caráter residual destas medidas se configura o que Netto (1999) denomina de pobres politicas sociais para os pobres, ou de pequenas soluções ad hoc para grandes problemas nacionais. Para o autor, tais medidas se direcionam a consolidar "uma espécie de pronto-socorro social, donde um enfrentamento à questão social caracterizado pelo focalismo das ações e seu caráter intermitente, derivado da natureza de uma intervenção basicamente emergencial (...) (NETTO, 1999, p. 88)".

A focalização quase que exclusivamente baseada em linhas absolutas da pobreza, muitas vezes com definição que beira a aleatoriedade por parte dos Policy Markets - reduzem a população alvo a segmentos muito inferiores aos que seriam alvo se adotasse um padrão mais relacional de definição da pobreza.

Não obstante, estas medidas de ações focalizadas se estruturam via ações descentralizadas, que longe de garantir uma relação mais horizontal entre os entes governamentais e o cidadão, se tornou lócus de reatualização de coronelismos e da cultura do favor típicas do clientelismo brasileiro, e o retrocesso a velhas formas de proteção social, ligadas e solidariedade, proteção comunitária etc.

Neste sentido, as iniciativas de ajuste neoliberal, longe de apontar um novo quadro de estruturação de políticas sociais com viés de ampliação de direitos, nos faz retroceder a formas pretéritas de proteção uma vez que, de um "conceito de Política Social como constitutiva do direito de cidadania, retrocedemos à uma concepção focalista, emergencial e parcial, onde a população pobre tem que dar conta dos seus próprios problemas". ISOARES, 2000, p.181) 
Um dos elementos centrais na agenda de reformas neoliberais destacados pelos seus ideólogos está o desfinanciamento das políticas sociais, via mecanismos dos Fundos Sociais. que posteriormente serão mantidos via desvinculação das receitas da união via DRU. Neste sentido, interpreta-se que a instituição destes mecanismos de realocação orçamentária para - pagamento de serviços da dívida teve como consequência mais imediata, nos termos de Laurell (2009), a "privatização seletiva6" das politicas sociais no Brasil, que se efetiva sob a existência de três condições:

a) criação de demanda por serviço privado - a propagada má qualidade de serviços públicos de saúde e educação torna a busca privada por estes serviços, quase um "fetiche" social; b) formas estáveis de financiamento ao mercado - mecanismos de isenção fiscal a empresas e financiamento subsidiado a população para consumo de serviços privados garante a mitigação do risco aos agentes privados; e c) consolidação do setor privado - Este elemento é primordial, pois o Brasil possui as maiores empresas latino americanas da área educacional e grandes corporações multinacionais da área de seguros privados de saúde e também previdência social, que estão dispostos a "desfrutar" da quebra da exclusividade do Estado nestes setores.

A solução encontrada pelos liberais, aqui no Brasil no século XXI ou na Europa nos séculos XVIII e XIX, ora aponta para um déficit educacional das massas empobrecidas, ora se encontra a gênese da pobreza na sua própria administração ineficaz, seja por ser focalizada de menos, seja por ser muito generosa e danosa ao desencadeamento do protagonismo e da livre iniciativa dos pobres, cessando-thes as suas "capacidades".

Ao se analisar, as soluções apontadas por alguns dos mais destacados intelectuais do social liberalismo, a superação da pobreza brasileira virá necessariamente do acesso educacional das massas. Nota-se que em momento algum, estes se põem a questionar as condições prévias de acesso a este nivel educacional ou mesmo a diferença de qualidade entre o serviço acessado pelo mais pobres através precarização dos serviços públicos. Como exemplo, um dos expoentes do pensamento social liberal no Brasil afirma que:

os que estudam o problema apontam a educação como o principal determinante isolado da nossa alta desigualdade de renda. Diferenças educacionais explicam cerca de $40 \%$ dos diferenciais de renda entre brasileiros. A taxa de retorno da educação no Brasil é de $16 \%$ ao ano. Ou seja, o rendimento futuro do estudante deverá subir, em média $16 \%$ para cada ano adicional completado. É dificil pensar em ativo com maior retorno do que a educação" (NERI, 2005, p.323)

\footnotetext{
${ }^{6}$ Quanto a privatização da área social sob a influência neoliberal, é necessário esclarecer que, "(...) apesar de a privatização ser o objetivo central, só interessa na medida em que a administração de fundos e a produção de serviços possam se converter em atividades econômicas rentáveis" (LAURELL, 2009, p.167). É o sentido do lucro que direciona a ocupação de atividades estatais por parte do setor privado, não somente a negativa da intervenção estatal como ação eficiente.
} 
Nota-se, portanto, que os teóricos do liberalismo identificam os limites do combate à pobreza no Brasil, assim como seu persistente crescimento em uma falha administrativa de educação que não atende aos mais pobres, situação sob a qual seria a medida mais eficaz em se intervir. Em suas posições, em momento algum se questiona o processo social que leva e este diferencial educacional entre os pobres, e os fundamentos que impossibilitam o acesso educacional a todos. Do mesmo modo, nota-se que os estudos negligenciam que os processos geradores da pobreza e desigualdade transcendem as possibilidades colocadas pelo aumento do "ativo" educacional.

Do mesmo modo, os autores defendem uma profunda reforma administrativa do Estado, que estaria ocupado em distribuir seus privilégios por uma elite que teria "(...) acesso privilegiado aos recursos e bens públicos, em detrimento dos pobres e miseráveis" (IETS, Apud, CASTELO, 2012, p.68) Nota-se, portanto, novamente uma identificação da pobreza e sua irresolutividade com falhas administrativas do Estado que necessita ser refuncionalizado.

Do mesmo modo, autores de vinculação liberal como Camargo (2004) identificam na pobreza brasileira um fator que the dinamiza e que condiciona a ineficácia de sua superação. Este autor aponta que a política social brasileira é marcada por "prioridades erradas e incentivos perversos". No âmbito desta análise, o cerne da pobreza está contido na má administração dos recursos disponibilizados via serviços sociais universais. Por consequência, em sua defesa de uma política restritiva e focalizada nos mais pobres, o autor defende que. a priori, os efeitos de uma politica social universal seriam, que "a distribuição dos recursos dos programas sociais estaria apenas replicando e validando a distribuição da renda gerada pelo funcionamento do mercado" (CAMARGO, 2004, p.69).

Ao afirmar ser considerável a quantia gasta com políticas de saúde educação e previdência social, o autor aponta que se o objetivo fosse erradicar a pobreza, seria necessário aproximadamente pouco mais de $4 \%$ do orçamento, e que a manutenção da desigualdade brasileira é fruto desta escolha equivocada de prioridades direcionadas ao conjunto de políticas sociais não focalizadas nos mais pobres. Neste sentido, em relação a possivel ineficiência da política social brasileira, que seria demasiado universalista, Camargo (2004) levanta um conjunto de questões

por que o gasto social brasileiro tem sido tão ineficiente para reduzir a pobreza e a desigualdade da distribuição da renda ao longo do tempo? Será que o problema está no fato de a clientela à qual os programas são dirigidos não ser correta para atingir este objetivo, ou o desenho dos programas é tal que os recursos não são efetivamente apropriados pela clientela-alvo, ou os incentivos gerados não são compativeis com os objetivos? (CAMARGO, 2004, p.70)

Em relação a estas perguntas o autor responde sustentando que o gasto social brasileiro, concentrado em determinadas áreas, privilegiaria a reduzida população idosa, com 
volumosos gastos previdenciários e assistenciais, relegando, na visão do autor, o segmento das crianças de 0 a 5 anos que deveriam ser atendidos via programas focalizados de transferência de renda somados a um reforço da educação básica.

Ao identificar a pobreza brasileira como resultado perverso das prioridades do gasto social, o autor reforça sua aposta no gerenciamento de programas e sua focalização, uma vez que para ele "Se um dos objetivos das políticas sociais é reduzir a desigualdade na distribuição da renda e a pobreza, estes programas deveriam se direcionar, prioritariamente, para os grupos de renda mais baixa (CAMARGO, 2004, p.72)".

No decurso de sua análise, o autor aponta, como resultado destas prioridades erradas, os incentivos perversos gerados pelas políticas sociais universais brasileiras que levariam a um desincentivo na formalização do mercado de trabalho brasileiro, e uma opção por não contribuir dos trabalhadores autônomos, em que estes estariam esperando chegar a 65 anos, para receber o BPC sem ter contribuido para a previdência social.

Deste modo, como resultado da improcedência do sistema brasileiro de proteção social, Camargo (2004), assim como os reformadores das leis dos pobres, identifica nos programas de combate à pobreza o círculo vicioso da própria pobreza. Ao defender a saída deste círculo vicioso da pobreza, aponta simplificadamente o sistema educacional básico como mola propulsora da superação da pobreza nas sociedades capitalistas, apontando a iniquidade da perspectiva de universalidade e de direitos sociais, uma vez que neste caso concreto do Brasil "o Estado não consegue financiar o principal mecanismo de ascensão social e econômica das familias pobres, que é a acumulação de capital humano através de boas escolas públicas (CAMARGO, 2004, p.76)".

Nota-se que a solução da pobreza parece se reduzir a esfera da redistribuição, do aporte de oportunidades e de acumulo de capital humano, cujo déficit resulta nas situações de pobreza. Nota-se que restam negligenciados nestas abordagens, os mecanismos estruturais das desigualdades sociais brasileiras, como a superexploração do trabalho e caráter dependente e associado do desenvolvimento do capitalismo no Brasil.

Por sua vez, pesquisadores do IPEA como Barros e Carvalho (2003), consideram que o insucesso das medidas desenvolvidas nas políticas sociais brasileiras se encontra na má modulação da focalização e na eficácia destas. Para os autores, ao focalizar ineficientemente. as politicas sociais brasileiras não conseguem identificar realmente as famílias mais pobres que seriam aquelas "merecedoras" da atenção social por parte do Estado. Partindo da suposição de que o nível do gasto social brasileiro é adequado aos objetivos das políticas sociais na redução da pobreza, Barros e Carvalho (2003) sustentam que estas corroborariam na redução das desigualdades se fossem dotadas de um maior grau de focalização e de uma consequente maior eficácia de suas ações. Neste sentido, em sua proposta de organização da proteção social brasileira, sustentam que: 
(...)podemos afirmar, com toda propriedade, que o Brasil é um pais com uma das politicas sociais mais abrangentes e, em grande medida, modernas. Pode-se dizer também que nossa politica social é bastante descentralizada e diversificada, embora seja óbvio que o grau de coordenação é ainda insuficiente. (BARROS E CARVALHO, 2003, p.05)

Diante da adequação dos níveis do gasto social e sua amplitude, os autores entendem não restar dúvida que a solução da persistente desigualdade social e pobreza brasileiras estaria ligada ao desenvolvimento de um sistema de seleção de beneficiários que garantisse uma maior otimização da focalização dos recursos nos cidadãos mais pobres. Do mesmo modo apontam que a maior eficácia seria dinamizada por um maior controle e avaliação das políticas sociais existentes, ou seja, uma resolução técnica do problema que impede a política social de chegar àqueles que em tese mais precisam, mas que não acessam, em tese por que setores privilegiados acessam indevidamente.

\begin{abstract}
Assim, estes autores propõem que a solução das iniquidades da política social brasileira passa pela necessidade de que "a eficácia relativa dos diversos programas fosse mapeada, [ a partir disso ] seria possivel concentrar os recursos disponiveis naqueles programas comprovadamente com maior impacto e, com isso, aumentar a efetividade da politica social. (BARROS E CARVALHO, 2003, p.09 destaques nossos)"
\end{abstract}

Continuando sua análise sobre a proteção social brasileira, os autores reforçam a necessidade de se garantir as prioridades das politicas sociais nos mais pobres. Para se concretizar esta prioridade, os autores sustentam que a focalização deve se operar em três frentes: 1) descentralização de recursos e atribuições aos entes subnacionais como estados e prioritariamente municipios; 2) regras claras de funcionamento dos benefícios, bem como de seus critérios de seleção para garantir uma maior adesão dos usuários; 3) mecanismo eficiente de seleção dos pobres entre os mais pobres.

Neste sentido, nota-se que, ao invés de questionar a gênese da pobreza nos processos produtivos e na natureza própria do Estado, os autores do mainstream da gestão e administração da pobreza no Brasil preferem identificar a pobreza como resultado de uma má administração ou de limites individuais dos pobres que seriam o público-alvo de seus esquemas, colocando a pobreza na culpa dos próprios pobres quanto a sua condição de pobreza. Neste sentido, estes autores entendem que a atitude "positiva" dos pobres é condição "sem a qual não" seria possivel enfrentar e solucionar a pobreza e suas multidimensionalidades na sociedade brasileira, ou em qualquer outro contexto, pois, para estes autores

Para que a pobreza seja realmente erradicada, é necessário que os pobres explorem as oportunidades disponiveis, no que precisam empenhar muito esforço. Em suma, a rota da saída da pobreza se baseia, necessariamente, no binômio oportunidade-esforço (BARROS E CARVALHO, 2003, p 14). 
Diante do quadro apontado pelos autores, a pobreza seria superada pelo aproveitamento das oportunidades geradas aos mais pobres dinamizando o seu maior ativo o capital humano, com a necessidade de se efetivar o esforço e merecimento por parte destas familias, uma vez que, "(...)A redução de esforço despendido por essas famílias diminui a eficácia dos programas e, por fim, a efetividade dos gastos sociais no combate à pobreza BARROS E CARVALHO, 2003, p 14)".

Como alternativa aos quais escapassem dessa ativação, por parte do esforço e merecimento, seriam atendidos para que se preparassem adequadamente para a efetividade dessa nova politica social implementada via esquemas focalizados de assistência social. Nesta lógica de política social, notamos que o protagonismo dos pobres seria fator primordial, sendo mister que "os segmentos mais pobres possam não só estar preparados para participar e se beneficiar do crescimento, mas, principalmente, possam contribuir para ele (BARROS E CARVALHO, 2003, p.15-16)", garantindo assim a necessária eficácia administrativa das medidas para a superação da pobreza no Brasil.

Visualiza-se a partir deste recurso analítico aos autores contemporâneos sobre a dinâmica da pobreza brasileira, que estes lançam mão do triplo movimento dos reformadores sociais do século XIX para propor a solução da pobreza na sociedade brasileira no século XXI.

Em um primeiro momento os autores identificam o problema da pobreza como resultado da inadequação dos esquemas de alívio à realidade social, como consequência pretendem reforma-los. Assim, identificam via processos "técnicos" que estes são iníquos, sendo ainda mecanismos que se desdobravam em estruturas reforçadoras e encasteladoras das situações de pobreza, impedindo via de regra a sua superação.

Em um segundo momento, os reformadores dos esquemas de alívio da pobreza apontam que, diante dos diagnósticos empreendidos no primeiro momento da reforma, seriam necessárias ações administrativas a se encaminhar no sentido de modular melhor a identificação daqueles pobres merecedores do atendimento da proteção social. Estes procedimentos reforçam uma perspectiva moralizadora no enfrentamento à pobreza, uma vez que a reforma tem como objetivo manifesto, evitar que se desencadeie "incentivos perversos" ao conjunto dos cidadãos, que diante das politicas sociais passariam a ter atitudes imprevidentes e reforçadoras da pobreza.

Em terceiro momento indicam prospectivamente as possibilidades de insucesso das medidas propostas na reforma das estratégias de enfrentamento da pobreza. Sinteticamente. sustentam que as possibilidades de insucesso da reforma dos serviços destinados ao alívio resultam em última instância de uma não adesão dos mais pobres a estes esquemas. Outro elemento destacado seria a existência de uma incapacidade individual, um déficit educacional que impossibilita aos mais pobres acumular o único bem que dispõem que seria o seu capital humano. Por último, identificam que o insucesso dos programas de alivio à pobreza advém de um não preparo por parte dos mais pobres para receber a política social reformada, tendo 
em vista a persistente ineficiência das medidas pretéritas que estes tiveram acesso. Enfim. escapa-se sempre de uma análise estrutural da gênese da pobreza e suas determinações fundantes no modo de produção capitalista, e reitera-se a solução administrativa de gestão da pobreza em suas manifestações multidimensionais.

Não obstante, esta forma de identificar a pobreza e seu enfrentamento é mistificada, limitada e vinculada às próprias caracteristicas do Estado sob a hegemonia burguesa no capitalismo. Desta forma, entende-se que, o Estado ao ser hegemonicamente condicionado pela ordem burguesa, está impedido de identificar e propor adequadamente a superação dos fundamentos da pobreza nesta ordem societária, pois este fato redundaria em seu fim, que seria acompanhado do fim da estrutura econômica que lhe sustenta, neste sentido deve se limitar a

descobrir apenas defeitos formais, casuais, da mesma [administração da pobreza], e tentar remediá-los. Se tais modificações são infrutiferas, então o mal social é uma imperfeição natural, independente do homem, uma lei de Deus, ou então a vontade dos individuos particulares é por demais corrupta para corresponder aos bons objetivos da administração. (MARX, 2011, p.149).

A partir desta análise o escopo de diagnósticos e propostas contidas sob o espectro social-liberal no Brasil não pode superar a sua identificação fragmentada e parcial, uma vez que é refém de um pressuposto mercado essencialmente superior na alocação e distribuição dos recursos sociais.

Essa superficial resposta às situações de pobreza proposta pelos liberais é o cerne da critica marxiana sobre a suposta tentativa burguesa de superar o pauperismo. Ao tempo em que a crítica marxiana identifica o cerne da pobreza na sociabilidade capitalista, vinculado à estrutura produtiva, aponta os limites do seu enfrentamento via medidas administrativas estatais, ou seja, restritas às medidas políticas no campo da distribuição.

Logo, as situações de pobreza, são enfrentadas como do âmbito da esfera individual, como falta de capacitações que resultam em situações específicas de pessoas que se encontram em extrema pobreza ou que tenham poucas condições de garantir o mínimo de subsistência, quando na verdade ultrapassam as opções individuais de cada sujeito em sua gênese, sendo uma característica estrutural do modo capitalista de produzir, não somente uma manifestação circunscrita à esfera da distribuição de riquezas.

\section{CONSIDERAÇÕES FINAIS}

Parece-nos mais factivel afirmar que a prevalência em investimentos sociais focalizados através de transferências de renda com valor baixo nas quais se encontram 
embutidas condicionalidades, aliada a baixa qualidade e precarização dos empregos gerados se torna antes uma estratégia de regulação da relação salarial a baixo custo, do interpretar que esta prevalência de transferências de renda sejam primordialmente uma articulada noção de desenvolvimento social que seja estruturalmente transformadora da realidade social.

Como se demonstra no desenvolvimento deste artigo, o projeto neoliberal recoloca na agenda, agora sob nova roupagem e intensidade, a negação das políticas sociais universalizantes e/ou que apontam para algum nível de desmercantilização do acesso aos direitos sociais. Nesta lógica, entende-se que as medidas empreendidas pelas reformas neoliberais estabelecem na ordem do dia das ações do Estado capitalista a remercantilização da proteção social institucional.

Em um aspecto mais imediato, as repercussões dessas agendas para as políticas sociais se operacionalizavam em uma privatização seletiva das políticas sociais, em que as políticas sociais com alguma possibilidade de exploração lucrativa via mercado são diretamente retiradas da responsabilidade estatal, ou em medidas mais capciosas, estas politicas sociais são precarizadas a fim de se esvaziar a sua oferta pública e sua legitimidade junto à população, tornando-as menos resistentes aos seus processos de privatização.

Diante dos elementos conceituais debatidos, se consolida um padrão de combate à pobreza sob o novo desenvolvimentismo que denominamos de distribuição horizontal de renda.

A distribuição horizontal da renda se dinamiza através da distribuição via fundo público de recursos oriundos de receitas fiscais que se concentram primordialmente sobre os rendimentos do trabalho, ou seja, a partir de uma estrutura altamente regressiva de tributação, que proporcionalmente incide muito fortemente sobre a renda do trabalho e consumo, e menos sobre fontes de renda oriundas de lucros e dividendos de capitais especulativos.

Tais processos garantem uma maior aproximação de renda entre os extratos mais pobres e os trabalhadores formalizados, e uma maior distância entre estes e as pessoas que se encontram no topo da pirâmide da distribuição de renda, uma vez não se fundam na tributação de rendimentos especulativos.

Logo, uma política social que se dinamiza em conceitos restritivos de pobreza, que acarreta a redução de pessoas consideradas pobres pelo próprio processo de focalização, reduzindo suas necessidades, e adequando-as ao quadro mais amplo de ajuste fiscal neoliberal. Visualizase ainda, que as tentativas de combate e reforma social, ambas colocadas em curso pelo bloco neoliberal advêm de um diagnóstico que se circunscreve a culpabilizar os pobres por sua condição, apontar uma inadequação dos esquemas de combate à pobreza precedentes, e propor uma readequação destes esquemas, passando sempre ao largo de questões centrais que fundamentam a geração da pobreza no âmbito da sociabilidade capitalista.

Este retorno do avanço da pobreza e da desigualdade nos últimos anos (desde o golpe institucional de 2016) demonstra que a estratégia neoliberal vem avançando na naturalização 
pobreza e no modo focalizado de programar políticas sociais com níveis mínimos de garantia de sobrevivência via transferências monetárias diretas, tais como as propostas de auxílio engendradas pelo governo Bolsonaro.

\section{REFERÊNCIAS BIBLIOGRÁFICAS}

ANDERSON. Perry. Balanço do Neoliberalismo. In: SADER, Emir: GENTILI. Pablo (Org.). PósNeoliberalismo: As Políticas Sociais e o Estado Democrático. Rio de Janeiro: Paz e Terra, 1995.

BARROS. Ricardo P. de: CARVALHO. Mirela de Desafios para a política social brasileira. Rio de Janeiro: Ipea, 2003 (texto para a discussão 985)

BEHRING. E. E BOSCHETTI, I. Política Social: fundamentos e história. 8ed. São Paulo: Cortez. 2010.

CAMARGO. Jose M. Política social no Brasil: prioridades erradas, incentivos perversos. In: São Paulo Perspec. [online]. 2004, vol.18, n.2, pp.68-77.

CHESNAIS. F. A finança mundializada. São Paulo: Boitempo. 2005.

COUTINHO. Carlos Nelson. Contra a corrente: ensaios de democracia e socialismo. São Paulo. Cortez. 2000.

COUTINHO. Carlos Nelson. Marxismo e política: a dualidade de poderes e outros ensaios. 2 2 Edição São Paulo: Cortez: 1996.

FALEIROS. V. de P. A Política Social do Estado Capitalista. São Paulo: Cortez, 2000.

HARVEY, D O neoliberalismo: história e implicações. Tradução de Adail Sobral e Maria Stela Gonçalves. São Paulo-SP: Edições Loyola. 2008.

HARVEY. D. A Condição Pós-Moderna: Uma Pesquisa sobre as origens da Mudança Cultural. SP: Ed. Loyola, 1993.

HAYEK, F.A. O caminho da servidão. 6a Ed São Paulo : Instituto Ludwig von Mises Brasil, 2010.

IAMAMOTO. Marilda Vilela. Os espaços sócio-ocupacionais do assistente social. In: Serviço Social: Direitos Sociais e competências profissionais. Brasilia: CFESS/ABEPSS. 2009. p. 341-376.

LAURELL. Asa Cristina. Avançando em direção ao passado. In: (Org). Estado e Políticas

Sociais no Neoliberalismo . 5 Ed São Paulo: Cortez, 2009.

MANDEL, E. O capitalismo tardio. São Paulo: Abril Cultural, 1982.

MARX, Karl. Glosas criticas marginais ao artigo "O rei da Prússia e a reforma social". De um prussiano. In: Germinal: Marxismo e Educação em Debate. Londrina, v. 3. n. 1. p. 142-155-; fev. 2011 
MESZAROS. I. Para além do capital: rumo a uma teoria da transição tradução Paulo Cezar Castanheira, Sérgio Lessa. - 1.ed. revista. - São Paulo: Boitempo, 2011.

MONTAÑO, C. E DURIGUETTO. M.L., Estado Classes e Movimentos Sociais. São Paulo: Cortez, 2010.

MONTAÑO. Carlos. Terceiro setor e questão social: critica ao padrão emergente de intervenção. 4. ed. São Paulo: Cortez, 2010.

NERI. Marcelo. Desigualdade e Desnvolvimento. In: Brasil em desenvolvimento: instituições, politicas e sociedade. Rio de Janeiro: Civilização Brasileira, 2005.

NETTO. José Paulo. FHC e a politica social: um desastre para as massas trabalhadoras. In: LESBAUPIN. Ivo (org). O desmonte da nação: balanço do governo FHC. Petrópolis. RJ: Vozes, 1999.

SOARES. L. T. R. Os custos sociais do ajuste neoliberal no Brasil. In: SADER. E. El ajuste estructural en América Latina. Costos sociales y alternativas. Buenos Aires: CLACSO, 2001. 